\title{
INTRODUCTION: ON THE ISSUE'S THEME AND ITS CONTRIBUTIONS
}

FILIP GURJANOV

One doesn't have to be a philosopher to observe that today's world is fast changing and becoming more and more interconnected. However, the meanings and implications of a modern globalised world are all but self-evident. They call for critical examination, to which philosophy - among other disciplines, but perhaps also together with them - can offer an important contribution. But not only that: it becomes a question for philosophy itself, i.e. for its own self-understanding today, how it will adapt to new challenges humanity is facing, whether it be the growing presence of technology and the new media in our lives; the emergency of ecological problems; or again the questions of migration and identity in a global world. By opening itself up to these relevant problems, philosophy itself undergoes a process of change. Certainly, there exist different ways for philosophy to reflect these modern challenges, and in return, be challenged to reflect upon itself. In our issue, we offer discussions, which centre on two notions, which will act as the common thread in our approach of thinking philosophically in a contemporary context. These two concepts are 'interculturality' and 'mediality'.

The emergence of 'intercultural philosophy' towards the end of the past century, which followed on from 'comparative philosophy', established a century earlier, ${ }^{1}$ mirrors what I believe to be a growing interest in expanding the scope of what is understood as 'philosophy' beyond a single cultural heritage. These, historically seen, still relatively new intellectual endeavours can be credited with opening the door for dialogue between texts and philosophies originating from

1 Wimmer Franz Martin, "Intercultural Philosophy - Problems and Perspectives", in Atti/Proceedings CIRPIT, Roccella Jonica, October 2012, p. 118. 
different traditions and cultures of thought. In addition, whilst taking intercultural or comparative method seriously represents no easy task, a task not every philosopher today is willing to embrace, there is a growing awareness and recognition amongst academics regarding the diversity and the wider cultural possibilities of contemporary philosophical thought.

At the same time, the contact and exchange between different parts of the world are becoming more and more our reality on a very practical level. While modern means of transport enable the rapid displacement of people and goods, new media accelerates the exchange of information, such as texts, sounds and images across the globe. But this process of 'mediatization' has different forms and implications. On the one hand, it enables access to more knowledge, fosters scientific exchange and offers a platform for facilitated communication and cooperation. On the other hand, it leads to controversial questions of the unity of a global culture in which diversity is levelled down, of the domination of certain cultural forms over others, of the spread of false information and an ever more endangered living environment we all share.

Our current issue of Interpretationes brings together a group of young international scholars whose research explores the themes of interculturality and mediality in diverse and thought-provoking ways. While some of the articles discuss the former theme as an invitation to further 'decolonise' philosophical thinking or to suggest ways in which it can help globalisation become a process worth affirming, others imply it either by discussing philosophies coming from different cultural backgrounds or, in a perhaps meontic way, by radically emphasising the importance of otherness. And whilst some of the authors explicitly thematise the latter theme of mediality as the role of the new media in constituting our 'picture' of the world today, ${ }^{2}$ others refer to it in the sense of a growing mutual interdependence between people and cultures, or again as our relationship with, and our embeddedness in, the natural environment. The various perspectives that the contributions to this issue open up on the theme of 'interculturality' and 'mediality' make us reconsider the possibilities of philosophical reflection today. Far from offering any definitive answers, the essays invite further discussions and suggest ways of finding orientation in thinking in the face of new uncertainties within the 21 st century. In what follows, I wish to briefly present the themes of the papers we have collected for this issue.

2 As a response to the growing importance of the new media, at the turn of the century in the German speaking world, different reflections around the notion of 'media' began to develop, which eventually formed a heterogeneous field of the 'philosophy of media'. Cf. Wiesing Lambert, "Was sind Medien?", in ders., Artifizielle Präsenz. Studien zur Philosophie des Bildes, Frankfurt am Main, 2005, pp. 149-162. 
Firstly, in his paper, Daeseung Park rethinks anthropology by opposing the Amerindian notion of 'multinaturalism' against the western idea of 'multiculturality'. Drawing primarily from the works of Eduardo Viveiros de Castro, Park demonstrates the advantages of regarding pluralism not in the context of representations, but rather of bodies. When perspectives are regarded as natural and not as cultural, they cannot be subjected to comparison in any pre-given categories. The task of 'counter-anthropology' then consists of offering a new method of 'translation' and 'comparison' beyond the plain of representations, which enables us to think the uniqueness of natural perspectives in their relationality and co-dependance with one another. Then, Wawrzyn Warkocki discusses mediality that constitutes the relationship between humans and nature in a thought-provoking comparative study between Heidegger and Watsuji. While revisiting a critical phenomenological reading that Watsuji offers with regards to early Heidegger, Warkocki further suggests that the later Heidegger's interpretation of $\varphi v$ vıৎ can cast a new light on our understanding of Watsujis's fûdo (風土), which represents an underexplored theme in the literature pertaining to the two great thinkers of the 20th century. Furthermore, with his text, Warkocki offers a model of a phenomenologically inspired ecological thought, situated in a dialogue between Europe and Japan. With a similar focus on the natural world, Gauthier Dierickx offers a unique exploration into how the practice of extreme sports suggests new conceptions of ontology that can be relevant in the contemporary context. On the one hand, practice can imply a mere mastering of nature, which results in an egotistic pursuit of what Gauthier characterises as 'zombie subjectivity'. On the other hand, certain practices of extreme sports can paint a very different ontological picture in which humans are an integral part of their natural environment; instead of exploiting it without limits, humans need to learn how to 'negotiate' with nature and maintain co-existence with it. To illustrate his point, Dierickx offers multiple examples of practices of extreme sports, which he supports with sources ranging from theoretical reflections to interviews and videos. Next, Oumar Dia explores the question of globalisation from the point of view of safe-guarding cultural heritages and identities. Drawing from a rich register of sources, but primarily from Édouard Glissant, Dia inquiries into the possibility of a 'third way': of affirming globalising tendencies, without losing one's local and individual sense of identity. In this context, Dia puts forth the concept of globality (mondialité), which he opposes against the levelling tendencies of globalisation (mondialisation). To maintain the diversity of cultural identities, both theoretical and ethical confrontations with the dynamism and the complexities of the modern world are necessary, which calls for mutual recognition and solidarity. Approaching the theme of mediality 
in the sense of 'new media', Daniella Prieto Arrubla problematises the appearance of humanity in her discussion of the 'politics of image'. Prieto Arrubla first brings Judith Butler's theory of the photographic frame into a fruitful dialogue with Georges Didi-Huberman's idea of resisting the 'enforced framing' by focusing on otherness, which according to Didi-Huberman can be found exemplified in Pasolini's L' article des lucioles. Following on from this, Prieto Arrubla offers analyses of Hito Steyer's theory of documentarism in a Colombian context, suggesting ways of using the new media to represent otherness, in a way that does justice to it. Finally, Prieto Arubla provides examples of ethical documentary practices, such as the portrayal of the prosecuted other in the case of the Second World War. Last but not least, Irene Breuer offers a rich analysis of the possibility of ethics based on the concept of 'vulnerability'. Focusing on the situation of the exiled person, Breuer establishes a convincing link between phenomenology (Husserl, Lévinas, Waldenfels) and authors like Butler, Nussbaum and MacIntyre. Since many people today are exposed to the suffering of others through the means of the new media, it becomes necessary to critically analyse the suitability of such access. Breuer concludes that countering the 'dehumanisation of the subject' is only possible by revitalising the 'face-to-face encounter'.

Finally, I wish to express my deepest thanks to everyone who contributed to making this issue possible: to my colleague and friend Elise Coquereau-Saouma, for sharing the work of editing this issue over the course of the past eight months; to Hanna Trindade and Karel Novotný for supporting the idea for this issue of Interpretationes from the very outset; to Marius Sitsch for his excellent and very active work as the journal's chief-editor; and lastly, to all the peer-reviewers and proof-readers of the French and the English texts for taking their precious time to help our issue achieve the aspired quality. Without all of you, 'interculturality and mediality' would never have become a reality.

In Prague, 7 February 2020

Filip Gurjanov is a recipient of a DOC Fellowship of the Austrian Academy of Sciences at the Institute of Philosophy at the University of Vienna and at the Faculty of Humanities of Charles University. His $\mathrm{PhD}$ research addresses the topic of photography and the photographic act. His interdisciplinary project combines photo-theoretical problems with concepts and theories within phenomenology (Heidegger, Fink, Sepp, Cheung) as well as Japanese philosophy (Nishida). Filip Gurjanov is a Serbian national and an alumnus of the master program "EuroPhilosophie Erasmus Mundus" (University of Bonn, Hosei University, Charles University).

E-mail: filip.gurjanov@protonmail.com 